\title{
Incidence of Viruses Infecting Winter Wheat in Alabama
}

Kira L. Bowen, John F. Murphy, and Kathy L. Flanders, Department of Entomology and Plant Pathology, Paul L. Mask, Department of Agronomy and Soils, and Ruhui Li, Department of Entomology and Plant Pathology, Auburn University, AL 36849

\begin{abstract}
Bowen, K. L., Murphy, J. F., Flanders, K. L., Mask, P. L., and Li, R. 2003. Incidence of viruses infecting winter wheat in Alabama. Plant Dis. 87:288-293.

The most important viral diseases of wheat are caused by Barley yellow dwarf virus (BYDV, strains PAV and MAV) and Cereal yellow dwarf virus (CYDV, strain RPV). Starting in 2000, winter wheat crops growing in northern, central, and southern Alabama were evaluated for the occurrence of BYDV-PAV and CYDV-RPV. In addition to these viruses, samples were tested for the presence of Soilborne wheat mosaic virus (SBWMV), Wheat spindle streak mosaic virus (WSSMV), and Wheat streak mosaic virus (WSMV). BYDV-PAV and CYDV-RPV were found throughout the state, alone or as co-infections, in $14.6 \%$ of the samples collected in 2000 and $12.2 \%$ of samples in 2001. PAV was found at a lower incidence than RPV (4.3 and 9.9\%, respectively) in 2000; however, in 2001, PAV was detected in $8.2 \%$ and RPV in $1.9 \%$ of the samples. There was less rainfall than the 30-year average during the 1999-2000 growing season, and this may have contributed to differences in the relative incidence of PAV and RPV between the 2 years. SBWMV, WSSMV, and WSMV also were detected in Alabama in 2, 7.8, and 5.4\% of the samples collected in 2000, respectively, and in 9.6, 34.3, and $18.5 \%$ of the samples collected in 2001, respectively. This is the first report of WSMV in Alabama winter wheat.
\end{abstract}

Additional keywords: Triticum aestivum

In Alabama, soft red winter wheat is valued at up to $\$ 12$ million annually (25). Although grain is only harvested from 32,000 to 36,000 ha of wheat in Alabama, the crop is planted on nearly 57,000 ha (25). Wheat is an integral crop in the Cover Crop Program of the Natural Resource and Conservation Service (1), and nearly all of the approximately 47,000 farmers in the state are likely to plant wheat as a forage or winter cover crop (P. Mask, unpublished data).

In the United States, some of the most damaging viral diseases of wheat are caused by Barley yellow dwarf virus (BYDV, strains PAV and MAV; genus Luteovirus) and Cereal yellow dwarf virus (CYDV, strain RPV; genus Polerovirus) $(4,26)$. Reductions in grain yield due to infection by BYDV and CYDV are estimated to range from 5 to $25 \%$ annually throughout the United States (29). However, research in Alabama has indicated that infections by these viruses may reduce grain yield by as much as $60 \%$, or 200 to $1,000 \mathrm{~kg} / \mathrm{ha}(27,28)$. Greater losses due to BYDV and CYDV apparently are experienced in the northern third of the state (19),

Corresponding author: K. L. Bowen

E-mail: kbowen@acesag.auburn.edu

Accepted for publication 22 October 2002.

Publication no. D-2003-0115-01R

(C) 2003 The American Phytopathological Society where more than $50 \%$ of the wheat in Alabama is grown. In addition, these viruses have been shown to increase the susceptibility of wheat to Septoria leaf blotch (3) and to reduce plant growth (5).

BYDV and CYDV originally were distinguished based on the specificity of vector transmission (20). Aphid species are vectors for BYDV and CYDV, and those identified in Alabama include greenbug (Schizaphis graminum), English grain aphid (Sitobion avenae), bird cherry-oat aphid (Rhopalosiphum padi), rice root aphid ( $R$. rufiabdominalis), and corn leaf aphid (R. maidis) $(12,28)$. R. padi, $R$. rufiabdominalis, and $S$. avenae, but not $S$. graminis, efficiently transmit BYDV-PAV, CYDV-RPV, or both in South Carolina (9). Temperatures affect transmission efficiency by these vectors, and there appear to be geographic differences in vector specificity and disease virulence of viral strains (13). Therefore, generalizations cannot be made about the disease severity or viral strains found in Alabama based on aphid vectors that might be observed.

Wheat samples collected in Alabama in 1975 were shown to contain BYDV-PAV (7). In studies conducted prior to 1993 in Arkansas (18), Louisiana (24), and South Carolina (9), BYDV-PAV was detected at greater incidence than CYDV-RPV, and BYDV-MAV was rarely detected. More recently, BYDV-PAV and CYDV-RPV were detected from an average of 24 to $39 \%$ of symptomatic wheat samples collected throughout Alabama (27). BYDV-MAV was not detected in wheat samples collected in Alabama from 1993 to 1995 (27).

Growers and extension personnel are aware of potential losses in winter wheat due to infections by BYDV and CYDV in Alabama. However, information generally is lacking about the occurrence of other viruses in wheat grown in Alabama. Wheat spindle streak mosaic virus (WSSMV, genus Bymovirus) has been identified in wheat in Georgia, and symptoms similar to those described for infection by WSSMV have been seen on wheat in Baldwin County, AL (11). WSSMV is vectored by Polymyxa graminis Ledingham, a soilborne oomycete, as is Soilborne wheat mosaic virus (SBWMV, genus Furovirus), the latter having been found throughout Alabama (14). Wheat streak mosaic virus (WSMV, genus Tritimovirus) causes symptoms similar to those caused by WSSMV, but WSMV is vectored by the wheat curl mite (Aceria tosichella) $(21,29)$.

Symptoms due to BYDV and CYDV infections have been observed in winter wheat in Alabama for years, but seem to have increased in recent years. In small grain variety trials at 10 locations in the state during the spring of 1999, the average incidence of plants showing reddening and purpling of leaves typically associated with infection by these viruses was almost $100 \%$, compared with $<25 \%$ in the preceding year (8). These observations raised concern about an increase in the incidence of BYDV and CYDV in wheat in Alabama. A survey was initiated to confirm the incidence of various viruses in Alabama winter wheat, and to determine factors that may affect the relative incidence of these viruses. Over a 2-year period from fall 1999 through spring 2001, winter wheat crops grown throughout the state were evaluated for the occurrence of BYDV-PAV and CYDV-RPV. In addition, samples were tested for the presence of SBWMV, WSSMV, and WSMV.

\section{MATERIALS AND METHODS}

In this report, the disease caused by infection of wheat by BYDV, CYDV, or both is referred to as yellow dwarf (YD), unless referring specifically to one of the viral diseases (e.g., BYD or CYD). In addition, analyses carried out to identify either BYDV or CYDV were specific for strains PAV and RPV, respectively. Therefore, all subsequent references to BYDV-PAV and CYDV-RPV refer to these viruses as PAV and RPV, respectively. 
Winter wheat samples were collected in April and May 2000 from one to four fields in 13 counties (total $=29$ fields) in northern, southern, and central Alabama; and in April and May 2001 from one to four fields in 12 counties (total $=25$ fields) in northern and central Alabama (Figs. 1 and 2). Fields were selected with the help of County Extension personnel, based on grower cooperation and, wherever possible, the cultivar was identified.

Within each selected field, V-shaped or polygonal patterns were walked as samples were collected. Samples were collected without regard for presence or absence of disease symptoms, at predetermined distances between samples ( 20 to $40 \mathrm{~m}$, depending on field size). For each sample, two approaches were used to assess virus infection in wheat plants. First, individual plants were assessed visually by rating the flag leaf for YD symptoms using a 0-to-5 scale, where $0=$ no distinguishable YD symptoms, $1=$ trace of reddening or yellowing on the tip of the flag leaf, $2=$ onefourth to one-third of the flag leaf discolored with evidence of leaf curl; $3=$ onethird to one-half of the flag leaf discolored and curling, $4=$ one-half to three-fourths of the flag leaf discolored and curling, and 5 = flag leaf completely discolored and curled. Each plant also was rated for stunting as a percentage reduction in height relative to plants in the immediate area (i.e., $5 \mathrm{~m}$ in all directions). Second, flag leaves were collected from plants that had been assessed visually, placed in individual paper envelopes, sealed in plastic bags, placed on ice in an insulated cooler, and returned to the laboratory where they were stored at $-20^{\circ} \mathrm{C}$ until processed for the presence of specific viruses by enzymelinked immunosorbent assays (ELISA).

Visual and ELISA virus assessments were performed on 25 plants from each of 28 fields sampled in 2000. (Visual assessment data were lost for the twenty-ninth field in 2000.) In 2001, 25 plants from each of 25 fields were assayed for virus infection by ELISA. Because of the occurrence of dryland foot rot (caused by Fusarium spp.) in many 2001 winter wheat crops, YD symptoms could be discerned in only 13 fields. In addition to collection of flag leaves for analysis by ELISA in 2001, individual heads were collected from each sampled plant for additional tissue for ELISA. Head tissue was included to improve the probability of detecting BYDV or CYDV in samples (S. Gray, personal communication). During sampling, aphid density was noted and recorded on a scale of 0 to 3 , where $0=$ none observed, $1=1$ to several aphids observed in field, $2=1$ to several aphids observed on several of the sampled plants, and $3=>10$ aphids observed on several of the sampled plants.

All leaf or leaf plus head samples were tested for PAV and RPV by ELISA. In addition, every other sample from each field (12 or 13 per field) also was tested by ELISA for the presence of WSSMV, SBWMV, and WSMV. Detection of each virus was carried out using an alkaline phosphatase-based ELISA kit from Agdia, Inc. (Elkhart, IN) and performed according to the manufacturer's instructions. Each sample (leaf or leaf plus head) was ground in $2 \mathrm{ml}$ of extraction buffer (described in the manufacturer's instructions) using a motorized leaf squeezer with $100 \mu \mathrm{l}$ of extract added to the appropriate microtiter plate well. Substrate reactions (p-nitrophenyl phosphate at $1 \mathrm{mg} / \mathrm{ml}$ in $10 \%$ di- ethanolamine, $\mathrm{pH}$ 9.8) were allowed to develop for 30 min before absorbance values were recorded using a Sunrise Microtiter plate reader (Tecan U.S. Inc., Durham, NC) at $405 \mathrm{~nm}$. A sample was considered positive for the presence of the respective virus if the ELISA absorbance value was greater than the average plus three standard deviations of that of the healthy control wheat samples that were tested on each microtiter plate (23). Healthy wheat leaf tissue samples and known positive controls for each virus were obtained from Agdia, Inc. A positive

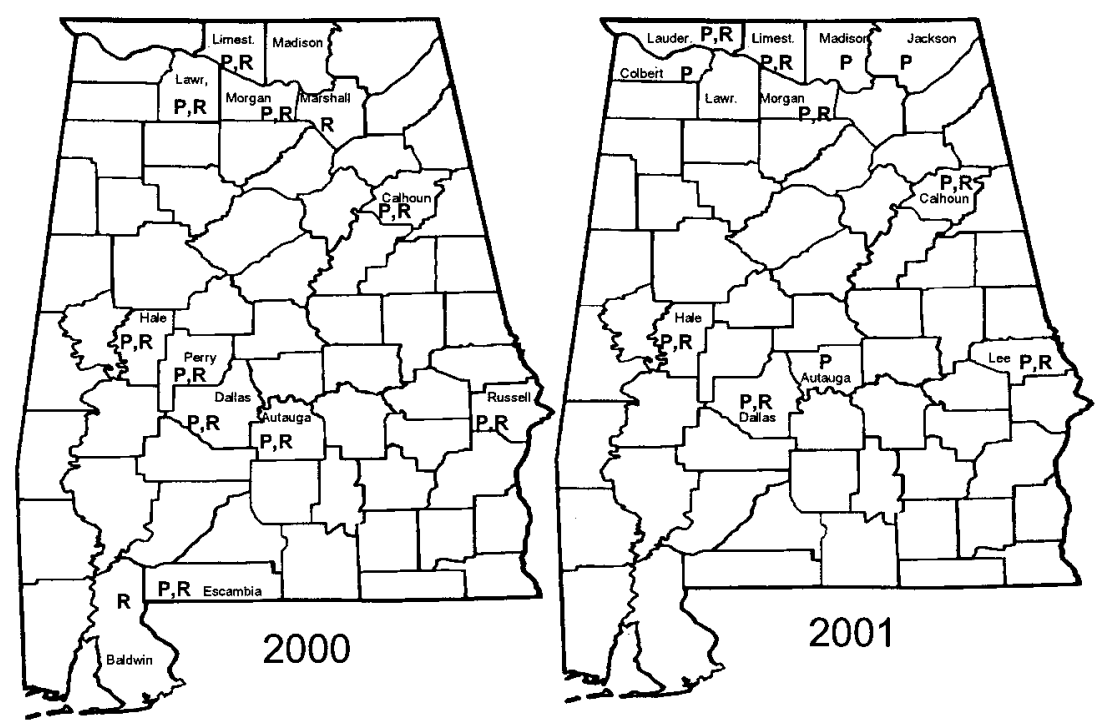

Fig. 1. Alabama counties from which winter wheat samples were assayed for Barley yellow dwarf virus (BYDV, strain PAV) and Cereal yellow dwarf virus (CYDV, strain RPV) in 2000 and 2001. P indicates BYDV-PAV and R indicates CYDV-RPV, detected by enzyme-linked immunosorbent assay from one or more leaf (2000) or leaf plus head (2001) samples. One to four fields were sampled in each county, and 25 samples were collected from each field.

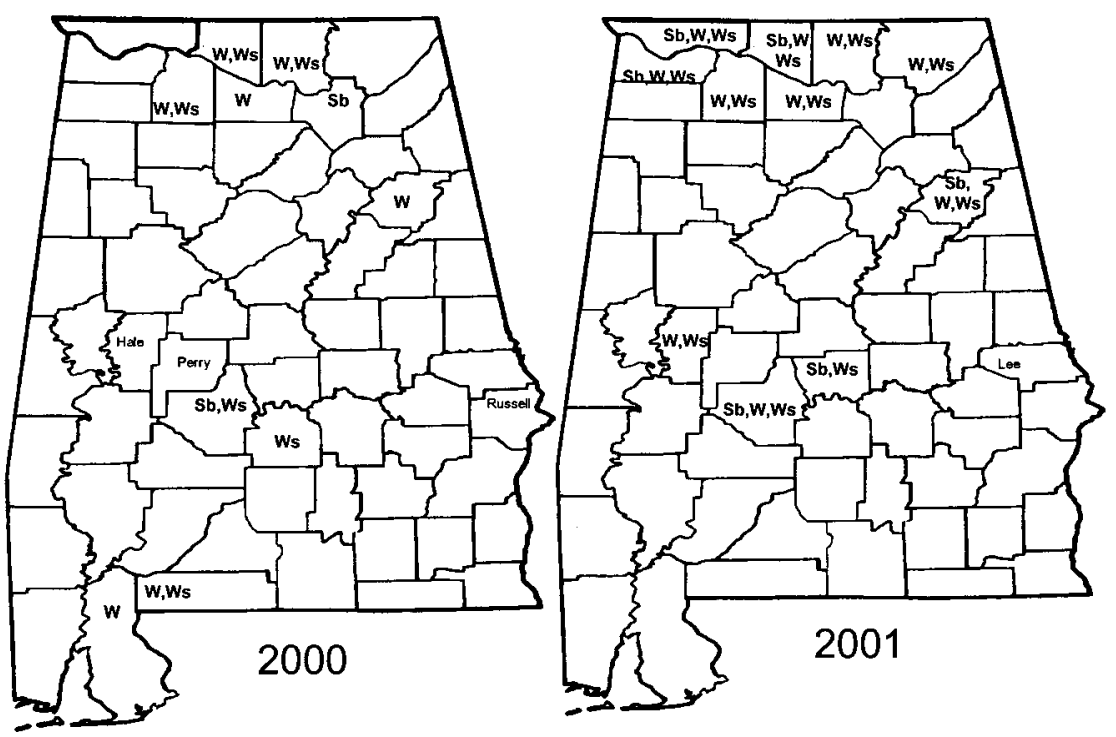

Fig. 2. Alabama counties from which winter wheat samples were assayed for Soilborne wheat mosaic virus (SBWMV), Wheat spindle streak mosaic virus (WSSMV), and Wheat streak mosaic virus (WSMV) in 2000 and 2001. Sb indicates SBWMV, Ws indicates WSSMV, and W indicates WSMV, detected by enzyme-linked immunosorbent assay from one or more leaf (2000) or leaf plus head (2001) samples. One to four fields were sampled in each county, and 25 samples were collected from each field. 
control for each virus was used in each ELISA system; this allowed us to show that each ELISA kit detected the homologous virus with no cross reaction to heterologous viruses tested for in this project.

Pearson's correlation coefficients (SAS release 6.12 , Cary, NC) were calculated between the incidence of viruses detected by ELISA and symptom ratings on individual leaves, and for the mean incidence and symptom rating per field. In addition, cor-

Table 1. Mean temperatures and cumulative rainfall from October to May for three locations in Alabama

\begin{tabular}{lcc}
\hline Location, year $^{\mathbf{a}}$ & Mean temperature $\left({ }^{\circ} \mathbf{C}\right)$ & Cumulative rainfall $(\mathbf{c m})$ \\
\hline Belle Mina, Limestone County & 12.1 & \\
30-year average & 12.4 & 120.0 \\
1999-2000 & 10.8 & 59.0 \\
2000-01 & 13.5 & 107.2 \\
Marion Junction, Dallas County & 14.6 & 116.8 \\
30-year average & 13.2 & 79.2 \\
1999-2000 & 16.2 & 124.0 \\
2000-01 & 16.5 & 116.8 \\
Fairhope, Baldwin County & 14.9 & 44.8 \\
30-year average & & 87.2 \\
1999-2000 & & \\
2000-01 & &
\end{tabular}

${ }^{a}$ Weather data are from Research and Extension Centers of the Alabama Agricultural Experiment Station System and are representative of the northern (Belle Mina), central (Marion Junction), and southern (Fairhope) winter wheat production areas in Alabama; 30-year average is calculated from 1963 to 1993.

Table 2. Incidence of Barley yellow dwarf virus (BYDV) strain PAV and Cereal yellow dwarf virus (CYDV) strain RPV in winter wheat fields sampled in Alabama in 2000 and $2001^{\mathrm{a}}$

\begin{tabular}{|c|c|c|c|c|c|}
\hline \multirow[b]{2}{*}{ Year, units (total no.) } & \multicolumn{4}{|c|}{ Numberb } & \multirow[b]{2}{*}{ Incidence $(\%)^{\mathrm{d}}$} \\
\hline & PAV & RPV & PAV + RPV & Neither & \\
\hline \multicolumn{6}{|l|}{2000} \\
\hline Leaves $(725)$ & 31 & 72 & 3 & 619 & 14.6 \\
\hline Northern fields (14) & 1 & 2 & 6 & 5 & 10.0 \\
\hline Central fields (8) & 3 & 1 & 4 & 0 & 21.5 \\
\hline Southern fields (7) & 2 & 3 & 0 & 2 & 17.2 \\
\hline \multicolumn{6}{|l|}{2001} \\
\hline Leaves + heads $(625)$ & 51 & 12 & 13 & 549 & 12.2 \\
\hline Northern fields (17) & 7 & 1 & 3 & 6 & 6.3 \\
\hline Central fields (8) & 2 & 0 & 5 & 1 & 24.5 \\
\hline
\end{tabular}

${ }^{\text {a }}$ Plants $(n=25)$ sampled per field and assayed for both viruses by enzyme-lined immunosorbent assay (ELISA). In 2000, the flag leaf was sampled; in 2001, the flag leaf plus the head were sampled from each plant.

b PAV = sample tested positive for only BYDV strain PAV by ELISA; RPV = sample tested positive for only CYDV strain RPV by ELISA.

' Sampled units. Northern fields were located north of latitude $33^{\circ} 28^{\prime}$ (approximately at Birmingham, AL), central fields were located between latitudes $33^{\circ} 28^{\prime}$ and $31^{\circ} 50^{\prime}$, and southern fields were south of latitude $31^{\circ} 50^{\prime}$ (approximately at Eufaula, AL).

${ }^{\mathrm{d}}$ Total mean incidence reflects the proportion of samples testing positive for PAV, RPV, or both of all samples ( 25 per field) from the region indicated.

Table 3. Numbers of winter wheat flag leaf samples, collected in Alabama in 2000, from which specific viruses were detected and with specified severity of symptoms of yellow dwarf at the time of sampling ${ }^{\mathrm{a}}$

\begin{tabular}{lrrrrrr}
\hline & \multicolumn{7}{c}{ Severity of yellow dwarf symptoms $^{\mathbf{b}}$} \\
\cline { 2 - 7 } Virus $^{\mathbf{c}}$ & $\mathbf{0}$ & $\mathbf{1}$ & $\mathbf{2}$ & $\mathbf{3}$ & $\mathbf{4}$ & $\mathbf{5}$ \\
\hline PAV & 9 & 6 & 3 & 2 & 0 & 10 \\
RPV & 60 & 6 & 0 & 0 & 2 & 2 \\
PAV + RPV & 2 & 0 & 1 & 0 & 0 & 0 \\
Neither & 470 & 87 & 8 & 2 & 7 & 23 \\
Total & 541 & 99 & 12 & 4 & 9 & 35 \\
\hline
\end{tabular}

${ }^{\text {a }}$ Flag leaf samples $(n=25)$ were collected from each of 28 fields in 12 counties across Alabama.

${ }^{\mathrm{b}}$ Symptoms were rated on a scale of 0 to 5 , where $0=$ no distinguishable yellow dwarf symptoms, 1 $=$ some reddening or yellowing on the tip of the flag leaf, $2=$ one-fourth to one-third of the flag leaf discolored with evidence of leaf curl; $3=$ one-third to one-half of the flag leaf discolored and curling, $4=$ one-half to three-fourths of the flag leaf discolored and curling, and $5=$ flag leaf completely discolored and curled.

c The presence of each virus was determined by enzyme-linked immunosorbent assay. PAV = Barley yellow dwarf virus strain PAV and RPV = Cereal yellow dwarf virus strain RPV. relation analysis was performed between aphid densities and incidence of YD symptoms in all fields. Correlation coefficients were considered significant when $P<0.05$.

\section{RESULTS}

Cultivar identification was not available for a majority of the fields sampled. Based on the cultivar information that was available, about one-third of the fields were planted to 'Coker 9663' and one-fifth to 'Coker 9803.' Additional cultivars planted included Coker 9705, Saluda, Jackson, and Gore.

In general, cumulative rainfall was 32 to $62 \%$ lower and temperature averages were 0.3 to $1.1^{\circ} \mathrm{C}$ higher than the 30 -year average at locations across the state from October 1999 through May 2000 (Table 1). In contrast, rainfall was similar to the 30 -year average, and temperatures tended to be lower than normal for the 2000-01 winter wheat growing season (Table 1).

In 2000, 725 leaves, sampled from 29 fields, were assayed for PAV and RPV. Overall, a greater number of samples were infected with RPV (9.9\%) than with PAV $(4.3 \%)$, and $0.4 \%$ of the leaf samples were infected with both viruses (total $=14.6 \%$; Table 2). Both PAV and RPV (individual and co-infections) were found in fields throughout the state (Table 2; Fig. 1), with greatest total mean incidence in fields in central counties. Neither PAV nor RPV was detected in leaves from two fields sampled in southern counties (one each in Baldwin and Escambia Counties), and from four fields sampled in northern counties (one each in Madison and Morgan Counties, and two in Lawrence County).

Disease severity in fields sampled in 2000 was generally low, with an average flag leaf severity rating of 0.4 and a mean of $1.4 \%$ stunting for all plants sampled. Ratings for aphid density in 21 fields indicated a significant negative correlation ( $r=$ $-0.46)$ between aphid density and severity of YD symptoms (i.e., low aphid densities were observed in fields with higher YD severity ratings). Severity ratings of leaves were not significantly correlated with detection of either PAV or RPV by ELISA. Specifically, 640 leaves had no or minimal symptoms of YD (rated 0 or 1), yet $13 \%$ of these leaves $(n=83)$ tested positive for PAV, RPV or both viruses (Table 3). Conversely, $6.9 \%$ (48 of 700) of the sampled leaves were rated as having moderate to severe symptoms of YD (ratings $\geq 3$ ), but PAV and RPV were undetected by ELISA in $67 \%$ (32 of 48) of the leaves. Mean flag leaf ratings for individual fields were positively correlated with incidence of PAV ( $n$ $=28, r=0.40$ ). There were no other significant correlations between detection of either PAV or RPV and symptoms of YD or stunting in 2000.

PAV was detected more frequently (8.2\% incidence) than RPV (1.9\% incidence) in the 625 plants sampled in 2001 
(Table 2). Co-infection by both viruses was detected in $2.1 \%$ of the samples, giving a total of $12.2 \%$ of the samples infected with one or both of these viruses. Neither PAV nor RPV was found in a single field sampled in central counties (specifically in Dallas County), and from five fields sampled in northern counties (one each in Jackson, Lawrence, and Morgan, and two in Limestone). The highest incidence of infection by PAV or RPV was detected by ELISA in samples from two fields in Lee County (64 and $80 \%$ for each field) in the central part of the state.

Leaf symptoms of YD were observed in only 5 out of 25 fields sampled in 2001. Apparently, widespread occurrence of dryland foot rot (caused by Fusarium spp.) masked symptoms and interfered with YD symptom rating. Plants in many of the fields sampled in 2001 had dry, bleached leaves by the soft dough stage. Visual estimates of the field incidence of YD was recorded for 14 fields, and averaged $7.4 \%$. Of these 14 fields, 12 had a low $(<2 \%)$ incidence of plants showing symptoms of YD; however, 2 fields in Lee County were estimated to have $50 \%$ symptomatic plants. Mean symptom ratings for each field were positively correlated with incidence of PAV ( $n=12, r=0.94)$ and with incidence of RPV ( $r=0.63)$. Correlation was not significant between observations of aphids and YD symptoms in 2001.

In 2000, SBWMV was detected in fewer than $2 \%$ of the leaves sampled (Table 4), and leaves that tested positive for this virus were from two fields, one each in Dallas (central) and Marshall (northern) Counties (Fig. 2). WSSMV was detected, either alone or in mixed infections, from samples collected in two fields in southern counties (both in Escambia County), two fields in central counties (one each in Autauga and Dallas Counties), and five fields in northern counties (one each in Lawrence and Madison and three in Limestone Counties). The mean incidence of WSSMV across all 29 fields was $7.8 \%$. Neither of these viruses was detected in the samples collected from 19 fields across the state, including fields in Baldwin and Escambia (southern), Perry (central), Calhoun, Lawrence, and Morgan (northern) Counties (Fig. 2). WSMV was detected in $5.3 \%$ of all samples, but from only six fields in northern Alabama and five fields in southern Alabama (Table 4; Fig. 2). Mixed infections detected in 2000 were RPV + WSSMV, $\mathrm{RPV}+\mathrm{WSMV}$, and WSSMV + WSMV. Symptoms due to these viruses were not rated.

In 2001, SBWMV, either alone or in mixed infections, was detected in $10.4 \%$ of all leaf plus head samples, specifically in samples from three fields in central counties (one field in Dallas and two in Autauga Counties), and six fields in northern counties (one each in Calhoun, Colbert, and Lauderdale, and three fields in Limestone Counties) (Table 4; Fig. 2). WSSMV was detected in $31.0 \%$ of the samples, specifically from 20 fields. WSSMV was not detected in samples from three fields in central counties (one in Dallas and two in Lee Counties), and two fields in northern counties (one each in Lauderdale and Morgan Counties). In 2001, WSMV, alone or in combination with other viruses, was detected in $18.7 \%$ of all samples (leaf plus head tissue), with the infected samples having been collected from 16 fields (Table 4). A greater number of mixed infections was detected in samples collected in 2001 compared with 2000, and included PAV + WSSMV, RPV + WSSMV, PAV + SBWMV + WSSMV, PAV + WSSMV + WSMV, SBWMV + WSSMV + WSMV, WSMV + WSSMV, SBWMV + WSSMV, and one sample in which all five viruses were detected. The incidences of SBWMV, WSSMV, and WSMV were lower in 2000 ( $<10 \%$ each) than in 2001 (10 to $31 \%$ each; Table 4).

Correlation analyses indicated that incidence of detection of SBWMV and WSSMV was negatively but not always significantly correlated with detection of PAV and RPV. Incidence of WSSMV was significantly negatively correlated with incidence of RPV in $2000(n=28, r=$ $-0.46)$ and $2001(n=24, r=-0.41)$.

\section{DISCUSSION}

Five viruses (PAV, RPV, SBWMV, WSSMV, and WSMV) were found in winter wheat samples collected across Alabama during the spring months of 2000 and 2001. Of these viruses, WSMV apparently has never been reported in the state, but PAV, RPV, SBWMV, and WSSMV have been reported $(7,11,14,19)$. In 2000 and 2001, the incidences of yellow dwarf viruses were similar, with 14.6 and $12.2 \%$, respectively, of individual wheat samples testing positive by ELISA.

PAV was detected at a lower incidence than RPV in 2000, but not in 2001. This contrasts with previous observations from the southeast region of the United States $(9,18,24,29)$. For example, in symptomatic samples collected in Alabama from 1993 through 1995, 31.1\% tested positive for PAV, whereas $7.9 \%$ were positive for RPV (29). In 850 randomly collected samples from South Carolina in 1997, 15 tested positive for PAV and only 2 samples were positive for RPV (9). There are several possible explanations for the higher incidence of detection of RPV than of PAV in the first year of our survey. For example, there may have been differences among the fields sampled in 2000 and 2001 relative to grassy weed species that serve as reservoirs for these viruses (10) or as secondary hosts for the aphid vectors of these viruses. Little is known about the vector-virus strain specificity situation in the southeast, and differences in aphid vector populations from year to year could affect the relative incidence of PAV versus RPV. Furthermore, prevailing weather conditions could have affected development and spread of these viruses differentially.

Moisture in the form of rainfall or irrigation has been shown to impact BYDV and CYDV occurrence $(2,16)$. For example, in drier areas of Australia, perennial grasses persist in irrigated fields, but not in dryland areas (16). These perennial grasses are

Table 4. Incidence of winter wheat infected with Soilborne wheat mosaic virus (SBWMV), Wheat spindle streak mosaic virus (WSSMV), or Wheat streak mosaic virus (WSMV) from fields surveyed in Alabama in 2000 and $2001^{\mathrm{a}}$

\begin{tabular}{|c|c|c|c|c|c|c|}
\hline \multirow[b]{2}{*}{ Year, sampled units (no.) ${ }^{\text {b }}$} & \multicolumn{2}{|c|}{ SBWMV } & \multicolumn{2}{|c|}{ WSSMV } & \multicolumn{2}{|c|}{ WSMV } \\
\hline & Number & Percent & Number & Percent & Number & Percent \\
\hline \multicolumn{7}{|l|}{2000} \\
\hline Leaves (358) & 6 & 1.7 & 28 & 7.8 & 19 & 5.3 \\
\hline Northern fields (14) & 1 & $2.8(0-38.5)$ & 5 & $12.2(0-100)$ & 6 & $5.4(0-25)$ \\
\hline Central fields (8) & 1 & $1.0(0-8.3)$ & 2 & $4.2(0-16.7)$ & 0 & 0 \\
\hline Southern fields (7) & 0 & 0 & 2 & $3.4(0-15.4)$ & 5 & $11.7(0-25)$ \\
\hline \multicolumn{7}{|l|}{2001} \\
\hline Leaves + heads (316) & 33 & 10.4 & 98 & 31.0 & 59 & 18.7 \\
\hline Northern fields (17) & 4 & $2.8(0-16.6)$ & 15 & $42.0(0-100)$ & 14 & $24.9(0-83.3)$ \\
\hline Central fields (8) & 3 & $24.0(0-92.3)$ & 5 & $19.4(0-69.2)$ & 2 & $4.0(0-16.6)$ \\
\hline
\end{tabular}

${ }^{\mathrm{a}}$ In all, 12 or 13 flag leaves in 2000 and 12 or 13 flag leaves plus heads in 2001 were sampled from randomly selected plants from each field. Number $=$ the total number of sampled units that tested positive by enzyme-linked immunosorbent assay (ELISA) for the indicated virus; percent $=$ the incidence of units that tested positive by ELISA for the indicated virus. Numbers between parentheses indicate the range in incidence of infection.

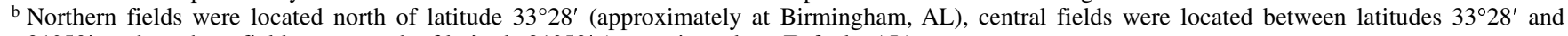
$31^{\circ} 50^{\prime}$, and southern fields were south of latitude $31^{\circ} 50^{\prime}$ (approximately at Eufaula, AL). 
where BYDV and CYDV and their vectors survive, and from which infections of BYDV and CYDV in nearby cereal crops are initiated (15). Because of the lower numbers and types of host plant reservoirs for the vectors and viruses in dry areas, it is possible that nearby cereal crops have fewer infections of BYDV or CYDV than those in regions with greater rainfall (16). Similarly, in the northwest region of the United States, expansion of irrigated wheat acreage has favored build-up of aphid populations, with a subsequent increase in the incidence of YD (2). Thus, in Australia and in the northwest region of the United States, previous observations indicate that more moisture, in the form of irrigation or rainfall, favors development of aphid populations and, therefore, spread of BYDV or CYDV.

In contrast, rainfall in Alabama is generally ample for production of winter wheat and there are usually abundant perennial grass hosts present throughout the year along roadsides and in the 10 million ha of grass forage. However, the summer of 1999 and the 1999-2000 winter wheat season was abnormally dry, with 30 to $60 \%$ less rainfall than the 30-year average at many locations throughout the state. The dry conditions of the first season of our survey may have been detrimental only to particular perennial grasses, which subsequently affected the relative occurrence of PAV versus RPV. The prevalence of PAV versus RPV can be affected by different grass species, as previously observed in Tasmania (10). In Alabama, studies are needed to evaluate the impact of different grasses on the prevalence BYDV and CYDV, and to evaluate the effect of weather patterns on these grass species.

The incidence of samples with moderate to severe symptoms of YD was lower than the incidence of samples that tested positive for PAV or RPV. In addition, no relationship was observed between the presence of these viruses in leaf or leaf plus head tissue and severity of YD symptoms on flag leaves. Other factors can cause symptoms similar to those attributed to $\mathrm{YD}$, and the lack of significant correlation may be associated with uneven distribution of the viruses in individual plants limiting the ability to detect some infections (6). Of greater concern was the samples that did not display YD symptoms, yet tested positive for PAV or RPV. These samples could have been collected from plants infected prior to sampling but late enough that symptoms had not yet developed (4). When the mean ratings for YD symptoms per field were compared with the mean incidence of viral infection in these fields, significant correlations were detected. Use of means increased the significance of the correlation between symptoms of YD and incidence of virus infections (22). However, correlation coefficients based on means were low $(r=0.40)$ in 2000 , or included relatively very few data points ( $n$ $=12$ ) in 2001. These results reinforce the need for confirmation of infection by BYDV or CYDV through diagnostic procedures other than visual assessment.

PAV and RPV were detected in mixed infections in a few samples in both years of this survey. A low incidence of samples with co-infections of PAV and RPV previously has been observed in the southeast region of the United States $(9,18,24)$. However, there was no consistency in symptoms observed among the samples with mixed infections. Thus, the symptoms caused by PAV and RPV cannot be differentiated visually nor do the viruses appear to have a synergistic effect on severity of YD symptoms in Alabama.

We did not find consistent significant correlations between aphid density and incidence of PAV or RPV as detected by ELISA in this study. However, aphid densities were rated only at the time of sampling and not at other times during winter wheat growth. Aphid species that vector PAV or PRV often can be found in winter wheat fields in autumn and winter months in Alabama, at which times infections by these viruses may be initiated (K. Flanders, unpublished data).

Current management options for YD in winter wheat in Alabama include seed and foliar insecticide treatments for control of aphid vectors. However, seed treatments are perceived as expensive by growers (28). Foliar insecticides do not provide season-long aphid control in wheat; therefore, it is necessary to apply insecticides when economically damaging populations of aphid vectors are present (28). The appropriate process for scouting wheat for aphid populations involves checking each field up to six times, and this is not common practice (K. Flanders, unpublished data). Scouting for aphids in winter wheat could be more efficient if information on the risk of aphid occurrences was available. Such information is available for the lesser cornstalk borer in peanut, and the scouting aid 'LCB-Days' helps with scheduling scouting efforts in that crop (17). More complete understanding of the ecology and epidemiology of PAV and RPV and their vectors is needed to develop such a decision aid for winter wheat.

Two viruses vectored by $P$. graminis, SBWMV and WSSMV, were detected in samples from winter wheat fields across the state in both years. The incidence of these viruses was greater in 2001 than in 2000. Development of $P$. graminis is favored by moist conditions, which were more prevalent in the 2000-01 winter wheat season than in the first season of our survey. Temperatures of 10 to $20^{\circ} \mathrm{C}$, which are optimal for development of SBWMV (29), are common through the winter wheat season in Alabama. Thus, moisture is probably more important than temperature in the epidemiology of SBWMV in the state. SBWMV and WSSMV can reduce yields substantially in parts of the United States (29). In Alabama, these two viral diseases of winter wheat are managed primarily through cultivar choice, although crop rotation and improving drainage also are recommended for minimizing infections of SBWMV and WSSMV (11).

WSMV, which was found in Alabama in this survey, can cause substantial wheat losses in the grain belt region of the United States (29). This virus was detected at a greater incidence in 2001 than in 2000. Little information is available about the effects of this virus on small grains in Alabama, and the widespread occurrence of this virus in this study warrants further investigation.

\section{LITERATURE CITED}

1. Anonymous. 2000. Cover crop. National Handbook of Conservation Practices, USDANRCS, Code 340.

2. Briggle, L. W. 1984. The barley yellow dwarf research program in the USA. Pages 141-144 in: Barley Yellow Dwarf. P. A. Burnett, ed. Mexico, D.F., CIMMYT.

3. Comeau, A., and Pelletier, G. J. 1976. Predisposition to Septoria leaf blotch in oats affected by barley yellow dwarf virus. Can. J. Plant Sci. 56:13-19.

4. D'Arcy, C. J., and Burnett, P. A. 1995. Barley yellow dwarf: A brief introduction. Pages 1-5 in: Barley Yellow Dwarf. P. A. Burnett, ed. Mexico, D.F., CIMMYT.

5. Delserone, L. M., Cole, H., Jr., and Frank, J. A. 1987. The effects of infections by Pyrenophora teres and barley yellow dwarf virus on the freezing hardiness of winter barley. Phytopathology 77:1435-1437.

6. French, R. 1995. Barley yellow dwarf: Diagnostic procedures and reagents. Pages 293305 in: Barley Yellow Dwarf: 40 Years of Progress. C. J. D'Arcy and P. A. Burnett, eds. American Phytopathological Society Press, St. Paul, MN.

7. Gildow, F. E. 1990. Current status of barley yellow dwarf in the United States: A regional report. Pages 11-20 in: World Perspectives on Barley Yellow Dwarf. P. A. Burnett, ed. Mexico, D.F., CIMMYT.

8. Glass, K. M., and Mask, P. L. 1998. The 1998 Alabama Performance Comparison of Small Grain Varieties. AAES Publ. Agron. Soils Dep. Ser. No. 213.

9. Gray, S. M., Chapin, J. W. , Smith, D. M., Banerjee, N., and Thomas, J. S. 1998. Barley yellow dwarf luteoviruses and their predominant aphid vectors in winter wheat grown in South Carolina. Plant Dis. 82:1328-1333.

10. Guy, P. L. 1988. Pasture ecology of barley yellow dwarf viruses at Sandford, Tasmania. Plant Pathol. 37:546-50.

11. Hagan, A. K., Mask, P. L., Gudauskas, R. T. and Collins, D. J. 1990. Wheat diseases and their control. Ala. Coop. Ext. Syst. Circ. ANR-543.

12. Halbert, S., and Voegtlin, D. 1995. Biology and taxonomy of vectors of Barley yellow dwarf viruses. Pages 217-258 in: Barley Yellow Dwarf: 40 Years of Progress. C. J. D'Arcy and P. A. Burnett, eds. American Phytopathological Society Press, St. Paul, MN.

13. Hewings, A. D., and Eastman, C. E. 1995. Epidemiology of barley yellow dwarf in North America. Pages 75-106 in: Barley Yellow Dwarf: 40 Years of Progress. C. J. D'Arcy and P. A. Burnett, eds. American Phytopathological Society Press, St. Paul, MN.

14. Jin, P., Gudauskas, R. T., Collins, D. J., 
Hagan, A. K., Mullen, J. M., and Mask, P. L. 1992. Soilborne wheat mosaic in Alabama. Ala. Agric. Exp. Stn. Highlights Agric. Res. 39(3):9.

15. Johnstone, G. R. 1995. Epidemiology of barley yellow dwarf in Australasia. Pages 129143 in: Barley Yellow Dwarf: 40 Years of Progress. C. J. D'Arcy and P. A. Burnett, eds. American Phytopathological Society Press, St. Paul, MN.

16. Jones, R. A. C., McKirdy, S. J., and Shivas, R. G. 1990. Occurrence of barley yellow dwarf viruses in over-summering grasses and cereal crops in Western Australia. Aust. Plant Pathol. 19:90-96.

17. Mack, T. P., Davis, D. P., and Lynch, R. E. 1993. Development of a system to time scouting for the lesser cornstalk borer (Lepidoptera: Pyralidae) attacking peanuts in the southeastern United States. J. Econ. Entomol. 86:164-173.

18. Mahmood, T., Gergerich, R. C., Milus, E. A., West, C. P., and D’Arcy, C. J. 1993. Barley yel- low dwarf viruses in wheat, endophyte-infected and endophyte-free tall fescue, and other hosts in Arkansas. Plant Dis. 77:225-228.

19. Mask, P., van Riessen, H., and Flanders, K. 1995. Gaucho, a new chemical registered for control of Barley Yellow Dwarf in wheat. ACES Pest Manage. Ser. Timely Info. Auburn University, AL

20. Rochow, W. F. 1969. Biological properties of four isolates of barley yellow dwarf virus. Phytopathology 59:1580-1589.

21. Slyhuis, J. T. 1955. Aceria tulipae Keifer (Acarina: Eriophydae) in relation to the spread of wheat streak mosaic. Phytopathology 45:116-128

22. Steel, R. G. D., and Torrie, J. H. 1980. Principles and Procedures of Statistics: A Biometrical Approach. McGraw-Hill, New York.

23. Sutula, C. L., Gillett, J. M., Morrissey, S. M., and Ramsdell, D. C. 1986. Interpreting ELISA data and establishing the positive-negative threshold. Plant Dis. 70:722-726.

24. Valverde, R. A., and Harrison, S. A. 1989.
Barley yellow dwarf viruses infecting oats and wheat in Louisiana. Plant Dis. 73:938.

25. Vanderberry, H. 2001. Alabama Agricultural Statistics. USDA Natl. Agric. Stat. Serv. Online publication by Ala. Agric. Stat. Serv.

26. van Regenmortel, M. H. V., Fauquet, C. M., Bishop, D. H. L., Carstens, E. B., Estes, M. K., Lemon, S. M., Maniloff, J., Mayo, M. A., McGeoch, D. J., Pringle, C. R., and Wickner, R. B. 2000. Virus Taxonomy: 7th Report of the International Committee on Taxonomy of Viruses. Academic Press, San Diego, CA.

27. van Riessen, H. W. 2002. Barley yellow dwarf virus and Cereal yellow dwarf virus in winter wheat in Alabama. Ph.D. dissertation, Auburn University, Alabama.

28. van Riessen, H. W., Mask, P. L., Flanders, K. L., Murphy, J. F., and Gazaway, W. S. 1998. Barley Yellow Dwarf In Small Grains. Ala Coop. Ext. Syst. Circ. ANR-1082.

29. Wiese, M. V., ed. 1987. Compendium of Wheat Diseases, 2nd ed. American Phytopathological Society Press, St. Paul, MN. 